\title{
The 2011 Nobel Prize in Physiology or Medicine
}

\author{
Hsi-Hsien Lin, PhD; Ming-Ling Kuo, PhD
}

$\mathrm{T}$ The innate immune responses serve as the body's first line of defense against invading pathogens. To be efficient in stopping subsequent microbial spread inside the body, the innate immune reactions must be spontaneous, fast and relatively non-specific. Thus, the innate immune system requires a preformed mechanism for identifying and eliminating microbes. It has long been proposed that innate immune effector cells possess sensors (cell surface receptors) that are capable of recognizing specific molecular structures unique to microbes. This forms the basis for the general theory of innate immune recognition proposed by the late Charles A. Janeway, Jr., who also predicted that the adaptive immune response is controlled by the more ancient innate immune system. (1) The brilliant insights of Dr. Janeway revolutionized our understanding of the immune system and formed the conceptual framework of the workings of the innate immune responses and the links between innate and adaptive immunity. The announcement of 2011 Nobel Prize in Physiology or Medicine to 3 leading immunologists (Jules A. Hoffmann, Bruce A. Beutler, Ralph M. Steinman) in a way is a testimony to the great contributions made by Charles A. Janeway, Jr. (Figure).

\section{Identification of innate immune receptors for pathogen-associated molecular patterns \\ Professor Jules A. Hoffmann started his scientif- ic career by working on the origins and roles of blood cells in the grasshopper, followed by biochem- ical studies of insect hormones. He finally focused on insect immunity, especially on the molecular and cellular aspects of the innate immune response of Drosophila.}

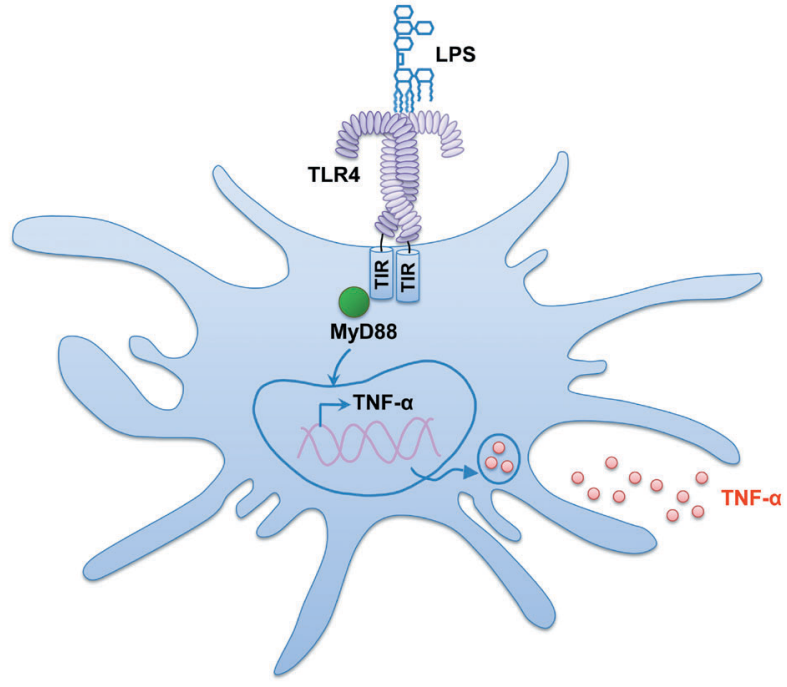

Figure The role of TLR4 in the innate immune response of DCs to LPS.

TLR4, the principal pattern recognition receptor for LPS, is highly expressed in DCs and responsible for the signal transduction that leads to the production of pro-inflammatory cytokines, such as TNF- $\alpha$. Abbreviations used: TLR4: tolllike receptor 4; DC: dendritic cells; LPS: lipopolysaccharide; TNF- $\alpha$ : tumor necrosis factor- $\alpha$. MyD88: myeloid differentiation primary response gene 88 ; TIR: toll/interleukin-1 receptor.

Interested in understanding how the innate immune system senses the presence of microorganisms, Prof. Hoffmann and colleagues employed $D$. melanogaster (fruit fly) as a model organism and identified the Toll receptor as a sensor for fungal infection in 1996. ${ }^{(2)}$ Toll was first identified to be important for the embryonic development of the fruit fly by Christiane Nusslein-Volhard, a 1995 Nobel

\footnotetext{
*H-H Lin and M-L Kuo contributed equally to this perspective.

From the Department of Microbiology and Immunology; Graduate Institute of Biomedical Sciences, College of Medicine, Chang Gung University, Taoyuan, Taiwan.

Received: Dec. 28, 2011; Accepted: Jan. 19, 2012

Correspondence to: Prof. Hsi-Hsien Lin, Department of Microbiology and Immunology; Graduate Institute of Biomedical Sciences, College of Medicine, Chang Gung University. 259, Wunhua 1st Rd., Gueishan Township, Taoyuan County 333, Taiwan (R.O.C.) Tel: 886-3-2118800 ext. 3321; Fax: 886-3-2118469; E-mail: hhlin@mail.cgu.edu.tw

Correspondence to: Prof. Ming-Ling Kuo, Department of Microbiology and Immunology; Graduate Institute of Biomedical Sciences, College of Medicine, Chang Gung University. 259, Wunhua 1st Rd., Gueishan Township, Taoyuan County 333, Taiwan (R.O.C.) Tel: 886-3-2118800 ext. 3319; Fax: 886-3-2118293; E-mail: mingling@ mail.cgu.edu.tw
} 
laureate in Physiology or Medicine. ${ }^{(3)}$ This finding opened an exciting new research avenue for the molecular mechanisms whereby innate immune cells recognize and distinguish "self" from "non-self" molecules. As in the fruit fly, humans have many Toll-like receptors (TLRs) which are now known to recognize a diverse array of pathogen-associated molecular patterns (PAMPs). ${ }^{(4)}$ One of the best examples of the interaction of cognate PAMPs and TLRs is that of lipopolysaccharide (LPS, endotoxin) and TLR-4 (Figure), which was identified by Bruce A. Beutler. ${ }^{(5)}$

An immunologist and geneticist, Beutler is best known for his pioneering work on inflammation and innate immunity. He was the first to isolate mouse tumor necrosis factor- $\alpha$ (TNF- $\alpha$ ) and to establish its important role as the inflammatory mediator in LPSinduced shock. ${ }^{(6,7)}$ His interest in the mechanism by which LPS activates innate immune cells led him to use TNF- $\alpha$ secretion as an assay endpoint for identification of LPS receptors. Using positional cloning techniques, Beutler and colleagues successfully mapped and identified the genetic alteration encoded by the Lps locus in endotoxin-tolerant mice. ${ }^{(5)}$ The mutated gene allele turned out to be TLR-4. The finding of TLR-4 as the membrane-spanning component of the LPS receptor complex led to further understanding of signaling pathways and identification of many relevant adaptor molecules important for the production of pro-inflammatory cytokines.

\section{Identification of dendritic cells that bridge innate and adaptive immune responses}

In 1973 whilc working in a macrophage laboratory, Dr. Ralph Steinman discovered a tree-like cell type distinct from conventional macrophages and hence named dendritic cells (DCs), which had the unique ability to trap intact antigens and present them to lymphocytes. ${ }^{(8,9)}$ This novel finding eventually bridged the gap in knowledge between the innate and adaptive immune systems. Professor Steinman studied this cell population and even tried to combine DC experimental therapies to treat his own pancreatic cancer. DCs comprise less than $1 \%$ of human blood cells or cells in mice spleen and at that time it took him almost 5 years to purify enough DCs for research. Despite these difficulties, Dr. Steinman was able to demonstrate that DCs are 100 times more potent than bulk splenocytes in initiating the activa- tion of quiescent lymphocytes. ${ }^{(10)} \mathrm{He}$ also demonstrated the existence of 2 functional stages of DCs, immature DCs which mainly capture and present antigens and mature DCs which co-stimulate activation of lymphocytes. ${ }^{(11,12)}$ In addition to the activation of T lymphocytes, Dr. Steinman's group found a role for DCs in controlling immune tolerance through DEC-205. The approach to generate antigen-specific $\mathrm{T}$ regulatory cells capable of preventing immune activation was also described recently. ${ }^{(13)} \mathrm{Dr}$. Steinman believed that DCs had a very high potential for application in medical regimens. In his first experiments using DCs for medical treatment, he removed DCs from cancer patients, charged the cells with tumor antigens and put them back into the patients. This approach has been approved by the US Food and Drug Administration. ${ }^{(14)}$ DC-based vaccines targeting infections diseases such as malaria, tuberculosis, and AIDS have also been tested. ${ }^{(15)} \mathrm{Dr}$. Steinman performed experiments to demonstrate how DCs function to initiate clonal expansion of the adaptive immune system and regulation of antigenspecific immune responses. His studies on DCs are essential for understanding collaboration and regulation between the two main branches of the immune systems.

The findings by these three laureates have brought us new insights into immune responses to infectious agents and tumors. They have provided the bases for new ideas in the development of vaccines and cancer therapies, and control of autoimmune diseases. Most importantly, their work has greatly deepened our understanding of fundamental immunology and opened many avenues for future research.

\section{Acknowledgements}

The authors would like to thank Yu-Wen Liang and Wen-Chih Wang for their artistic contribution in the Figure.

\section{REFERENCES}

1. Janeway CA Jr. Approaching the asymptote? Evolution and revolution in immunology. Cold Spring Harb Symp Quant Biol 1989;54 Pt 1:1-13.

2. Lemaitre B, Nicolas E, Michaut L, Reichhart JM, Hoffmann JA. The dorsoventral regulatory gene cassette spötzle/Toll/cactus controls the potent antifungal response in Drosophila adults. Cell 1996;86:973-83. 
3. Belvin MP, Anderson KV. A conserved signaling pathway: the Drosophila toll-dorsal pathway. Annu Rev Cell Dev Biol 1996;12:393-416.

4. Kimbrell DA, Beutler B. The evolution and genetics of innate immunity. Nat Rev Genet 2001;2:256-67.

5. Poltorak A, He X, Smirnova I, Liu MY, Van Huffel C, Du $\mathrm{X}$, Birdwell D, Alejos E, Silva M, Galanos C, Freudenberg M, Ricciardi-Castagnoli P, Layton B, Beutler B. Defective LPS signaling in $\mathrm{C} 3 \mathrm{H} / \mathrm{HeJ}$ and C57BL/10ScCr mice: mutations in Tlr4 gene. Science 1998;282:2085-8.

6. Beutler B, Greenwald D, Hulmes JD, Chang M, Pan YC, Mathison J, Ulevitch R, Cerami A. Identity of tumour necrosis factor and the macrophage-secreted factor cachectin. Nature 1985;316:552-4.

7. Beutler B, Milsark IW, Cerami AC. Passive immunization against cachectin/tumor necrosis factor protects mice from lethal effect of endotoxin. Science 1985;229:869-71.

8. Steinman RM, Cohn ZA. Identification of a novel cell type in peripheral lymphoid organs of mice. I. Morphology, quantitation, tissue distribution. J Exp Med 1973;137:1142-62.

9. Steinman RM, Cohn ZA. Identification of a novel cell type in peripheral lymphoid organs of mice. II. Functional properties in vitro. J Exp Med 1974;139:380-97.

10. Steinman RM, Witmer MD. Lymphoid dendritic cells are potent stimulators of the primary mixed leukocyte reaction in mice. Proc Natl Acad Sci USA 1978;75:5132-6.
11. Romani N, Koide S, Crowley M, Witmer-Pack M, Livingstone AM, Fathman CG, Inaba K, Steinman RM. Presentation of exogenous protein antigens by dendritic cells to $\mathrm{T}$ cell clones. Intact protein is presented best by immature, epidermal Langerhans cells. J Exp Med 1989;169:1169-78.

12. Schuler G, Steinman RM. Murine epidermal Langerhans cells mature into potent immunostimulatory dendritic cells in vitro. J Exp Med 1985;161:526-46.

13. Hawiger D, Inaba K, Dorsett Y, Guo M, Mahnke K, Rivera M, Ravetch JV, Steinman RM, Nussenzweig MC. Dendritic cells induce peripheral $\mathrm{T}$ cell unresponsiveness under steady state conditions in vivo. J Exp Med 2001;194:769-79.

14. Chang DH, Osman K, Connolly J, Kukreja A, Krasovsky J, Pack M, Hutchinson A, Geller M, Liu N, Annable R, Shay J, Kirchhoff K, Nishi N, Ando Y, Hayashi K, Hassoun H, Steinman RM, Dhodapkar MV. Sustained expansion of NKT cells and antigen-specific T cells after injection of alpha-galactosyl-ceramide loaded mature dendritic cells in cancer patients. J Exp Med 2005;201:150317.

15. Nchinda G, Kuroiwa J, Oks M, Trumpfheller C, Park CG, Huang Y, Hannaman D, Schlesinger SJ, Mizenina O, Nussenzweig MC, Uberla K, Steinman RM. The efficacy of DNA vaccination is enhanced in mice by targeting the encoded protein to dendritic cells. J Clin Invest 2008;118:1427-36. 